\title{
Left-sided portal hypertension caused by peripancreatic lymph node tuberculosis misdiagnosed as pancreatic cancer: a case report and literature review
}

\author{
Dajun $\mathrm{Yu}^{1+}$, Xiaolan $\mathrm{Li}^{1+}$, Jianping Gong${ }^{2}$, Jinzheng $\mathrm{Li}^{2}$, Fei Xie ${ }^{3}$ and Jiejun $\mathrm{Hu}^{2^{*}}$ (D)
}

\begin{abstract}
Background: Left-sided portal hypertension (LSPH) is an extremely rare clinical syndrome, and it is the only form of curable portal hypertension. It is primarily caused by pancreatic disease, and is associated with complications that cause spleen vein compression. Specific symptoms are often lacking, rendering it difficult to diagnose. Splenectomy is the main treatment for cases complicated by variceal bleeding, and the effects of treatment primarily depend on the condition of the primary disease.

Case presentation: The patient was a 29-year-old woman who was admitted to the hospital for repeated hematemesis and black stool. She had been misdiagnosed with pancreatic cancer 7 years prior. Combined imaging and endoscopic examination indicated varicose gastric fundus veins, a pancreatic mass, and enlarged peripancreatic lymph nodes. Laboratory investigations revealed reduced erythrocyte, platelet, and leukocyte counts, the interferon gamma release assay was positive, and liver function was normal. Abdominal exploration, splenectomy, varicose vein dissection, and lesion resection were performed via laparotomy. Postoperative biopsy analysis confirmed the diagnosis of lymph node tuberculosis. Based on the above-described factors, LSPH caused by peripancreatic lymph node tuberculosis was a diagnosed.

Conclusions: Herein we describe the first reported case of LSPH caused by peripancreatic lymph node tuberculosis. When left portal hypertension occurs simultaneously, peripancreatic lymph node tuberculosis is often misdiagnosed as pancreatic cancer. Further studies are necessary to develop a more favorable diagnostic method for pancreas masses and more advantageous therapy for LSPH, especially in cases caused by mechanical compression.
\end{abstract}

Keywords: Case report, Left-sided portal hypertension, Lymph node tuberculosis, Pancreatic cancer

\footnotetext{
* Correspondence: 310872192@qq.com

${ }^{\dagger}$ Dajun Yu and Xiaolan Li contributed equally to this work.

${ }^{2}$ Department of Hepatobiliary Surgery, The Second Affiliated Hospital of

Chongqing Medical University, 74 Linjiang Road, Yuzhong District,

Chongqing 400010, China

Full list of author information is available at the end of the article
}

C C The Author(s). 2020 Open Access This article is licensed under a Creative Commons Attribution 4.0 International License, which permits use, sharing, adaptation, distribution and reproduction in any medium or format, as long as you give appropriate credit to the original author(s) and the source, provide a link to the Creative Commons licence, and indicate if changes were made. The images or other third party material in this article are included in the article's Creative Commons licence, unless indicated otherwise in a credit line to the material. If material is not included in the article's Creative Commons licence and your intended use is not permitted by statutory regulation or exceeds the permitted use, you will need to obtain permission directly from the copyright holder. To view a copy of this licence, visit http://creativecommons.org/licenses/by/4.0/ The Creative Commons Public Domain Dedication waiver (http://creativecommons.org/publicdomain/zero/1.0/) applies to the data made available in this article, unless otherwise stated in a credit line to the data. 


\section{Background}

Lymph nodes are the sites most frequently affected by Mycobacterium tuberculosis outside the lung [1-4], but intra-abdominal lymph node tuberculosis is an extremely rare disease and most cases are associated with immunosuppression [5]. Left-sided portal hypertension (LSPH) is a rare clinical syndrome that can lead to bleeding from isolated gastric varices with normal liver function [6]. The most common causes of LSPH include chronic pancreatitis, pancreatic pseudocysts, and various pancreatic tumors [7-12].

Most patients with LSPH are asymptomatic, and only a few patients exhibit isolated gastric varices, ruptures, and fatal bleeding caused by splenic vein obstruction resulting from thrombosis, mechanical compression, tumor invasion, and metastasis [7-14]. It is difficult to diagnose LSPH [15], and bleeding from LSPH is frequently fatal $[8,13,16-19]$. Diseases resulting in LSPH often need to be distinguished from pancreatic cancer, therefore it is necessary for due attention to be paid to the diagnosis and treatment of LSPH [20-22]. Herein we describe a case of LSPH caused by peripancreatic lymph node tuberculosis that had been misdiagnosed as pancreatic cancer 7 years prior.

\section{Case presentation}

The patient was a 29-year-old woman who had undergone debridement and drainage for cervical lymph node tuberculosis 9 years prior to the current presentation. She had been examined 7 years prior to the current presentation via abdominal computed tomography (CT) at another hospital due to abdominal pain. That CT examination revealed a mass in the pancreas body and enlarged lymph nodes in the abdominal cavity. Understandably, at that time it was suspected that she had pancreatic cancer with lymphatic metastasis. Apart from the CT report however, the specific clinical examination index of the patient compiled at the other hospital was unavailable. Two years after the symptoms had been relieved via treatment with traditional Chinese medicine, the patient began experiencing repeated vomiting and melena that had persisted for the subsequent 5 five years; up to the time of the current presentation. At our hospital she stated that her psychological status, appetite, and sleep were normal, and she exhibited ochrodermia but no fever, jaundice, petechiae, or ecchymoses. On physical examination her general condition was good, and there was no abdominal tenderness, abdominal muscle tension, rebound pain, abdominal mass, or hepatomegaly. There was also no swelling of the cervical, supraclavicular, axillary, or inguinal lymph nodes.

To clarify the cause of the patient's condition, biochemical blood analysis and routine blood examinations were performed. Adenosine deaminase and liver function were within normal ranges (Table 1), but erythrocyte, platelet, and leukocyte counts were reduced (Table 2). Alpha fetal protein, tumor associated antigen 125, and tumor associated antigen 199 results were normal. Tests for human immunodeficiency virus, hepatitis $\mathrm{B}$ virus, hepatitis $\mathrm{C}$ virus, and $M$. tuberculosis infection were negative, but an interferon gamma release assay was positive.

To further aid in the diagnosis, imaging examinations including abdominal non-contrast and contrastenhanced CT, CT angiography (CTA), CT venography, and portal-phase three-dimensional vascular reconstruction were performed. Both non-contrast and contrastenhanced CT indicated non-obvious enhancement in both the arterial and venous phases, and a heterogeneous, non-vascular, low-density mass was depicted in the lower margin of the pancreas body with poorly defined edges and dimensions of approximately $3.1 \times 2.0$ $\mathrm{cm}$ (Fig. 1a). An intumescent spleen and multiple nodular dense shadows around the pancreas, hepatic hilar region, and mesentery were also visible on CT (Fig. 1a). CTA, CT venography, and portal-phase threedimensional vascular reconstruction depicted an enlarged splenic vein, narrowed initial section of the splenic vein, and tortuous gastric veins (Fig. $1 \mathrm{~b}$ and $\mathrm{d}$ ). Gastroscopy detected varicose veins under the gastric fundus mucosa (Fig. 1c), but the esophageal mucosa was smooth. Chest CT was conducted to investigate a potential history of tuberculosis, and it depicted a cable-like

Table 1 Blood biochemical results

\begin{tabular}{|c|c|c|c|}
\hline Variable & Result & Units & Reference \\
\hline Total bilirubin & 9.4 & umol/L & $0.0-22.3$ \\
\hline Direct bilirubin & 7.8 & umol/L & $0.0-8.6$ \\
\hline Indirect bilirubin & 1.6 & umol/L & $0.0-17.1$ \\
\hline Serum total bile acid & 10.5 & umol/L & $0.0-10.0$ \\
\hline Alanine aminotransferase & 21.0 & $U / L$ & $5.0-40.0$ \\
\hline Aspartate aminotransferase & 25.0 & $U / L$ & $5.0-40.0$ \\
\hline Alkaline phosphatase & 50 & $U / L$ & $45-125$ \\
\hline Glutamyl transpeptidase & 11 & $U / L$ & $5-60$ \\
\hline Lactate dehydrogenase & 209 & $U / L$ & $100-350$ \\
\hline Cholinesterase & 4426 & $U / L$ & $3930-1380$ \\
\hline Adenosine deaminase & 10.0 & $U / L$ & $4.0-22.0$ \\
\hline Alpha-I-fucosidase & 26.0 & $U / L$ & $0.0-40.0$ \\
\hline Monoamine oxidase & 3.0 & $U / L$ & $0.0-12.0$ \\
\hline Prealbumin & 181 & $\mathrm{mg} / \mathrm{L}$ & $150-380$ \\
\hline Total protein & 65.8 & $g / L$ & $65.0-85.0$ \\
\hline Albumin & 44.4 & $g / L$ & $40.0-55.0$ \\
\hline Globin & 21.4 & $g / L$ & $20.0-40.0$ \\
\hline Albumin/Globin & 2.07 & & $1.20-2.40$ \\
\hline
\end{tabular}

Liver function and other blood biochemical indexes were normal 
Table 2 Routine blood examination

\begin{tabular}{|c|c|c|c|}
\hline Variable & Results & Units & Reference \\
\hline White blood cells & 1.81 & ${ }^{*} 10 \sim 9 / L$ & $3.50-9.50$ \\
\hline Red blood cells & 2.60 & ${ }^{*} 10 \sim 12 / L$ & $3.80-5.10$ \\
\hline Hemoglobin & 67 & $g / L$ & $115-150$ \\
\hline Platelets & 50.00 & ${ }^{*} 10 \sim 9 / L$ & $85.00-350.00$ \\
\hline Hematocrit & 23.5 & $\%$ & $35.0-45.0$ \\
\hline Mean corpuscular volume & 90.40 & $f L$ & $82.00-100.00$ \\
\hline Mean corpuscular hemoglobin & 25.80 & $\mathrm{pg}$ & $27.00-34.00$ \\
\hline Mean corpuscular-hemoglobin concentration & 285.000 & $g / L$ & $316.00-354.00$ \\
\hline Red cell volume distribution width-CV & 17.90 & & $0.00-15.00$ \\
\hline Red cell volume distribution width-SD & 59.10 & & $0.00-45.00$ \\
\hline Neutrophil ratio & 77.90 & $\%$ & $40.00-75.00$ \\
\hline Lymphocyte ratio & 15.50 & $\%$ & $20.00-50.00$ \\
\hline Monocyte ratio & 5.50 & $\%$ & $3.00-10.00$ \\
\hline Eosinophil ratio & 1.10 & $\%$ & $0.40-8.00$ \\
\hline Basophil ratio & 0.00 & $\%$ & $0.00-1.00$ \\
\hline Neutrophils & 1.41 & ${ }^{*} 10 \sim 9 / \mathrm{L}$ & $1.80-6.30$ \\
\hline Lymphocytes & 0.28 & ${ }^{*} 10 \sim 9 / L$ & $1.10-3.20$ \\
\hline Monocytes & 0.10 & ${ }^{*} 10 \sim 9 / L$ & $0.10-0.60$ \\
\hline Eosinophils & 0.02 & ${ }^{*} 10 \sim 9 / L$ & $0.02-0.52$ \\
\hline Basophil & 0.00 & ${ }^{*} 10 \sim 9 / L$ & $0.00-0.06$ \\
\hline
\end{tabular}

White blood cells, red blood cells, hemoglobin, and platelets were reduced, as well as red cell volume distribution width widening

increased density of flaky shadows in the posterior segment of the upper lobe tip of the left lung. Based on the above results the patient was diagnosed with LSPH. Due to the nature of the mass in the pancreas however, it was unclear whether it was tuberculosis, a tumor, or another lesion. In the present case the mass was located in the lower margin of the pancreas body, and peripancreatic blood vessels were abundant, so it is difficult and dangerous to operate aspiration. According to our Multiple Disciplinary Team, endoscopic ultrasoundguided fine-needle aspiration biopsy (EUS-FNAB) was not applicative.

Due to repeated hematemesis symptoms, after a blood transfusion and the improvement of anemia the patient underwent a splenectomy and perigastric fundus vascular dissection, and a lesion excision was performed for biopsy. Intraoperatively an enlarged spleen with dimensions of approximately $34 \times 25 \times 15 \mathrm{~cm}$ was observed. After dissociating the peritoneal adipose tissue it was evident that the left gastric vein, right gastric vein, left gastroepiploic vein, and right gastroepiploic vein were extensively tortuous and dilated (Fig. 2a). As the dissection deepened, swelling of the lymph nodes at the greater curvature, hepatoduodenal ligament, and lower margin of the pancreas were apparent (Fig. 2b). Intraoperative ultrasound suggested that the mass occupying the lower margin of the pancreas was an abscess.
Because it exhibited a caseous necrosis profile the sample was submitted for biopsy, and a necrotizing granulomatous lymphadenitis compatible with tuberculosis was observed (Fig. 2c and d). After obtaining these results microbiological analysis was performed, and Ziehl-Neelsen staining was suspiciously positive. Therefore, the diagnosis of LSPH caused by lymph node tuberculosis was confirmed. Based on the newly generated clinical evidence it was concluded that the patient's diagnosis 7 years prior should have been peripancreatic lymph node tuberculosis rather than pancreatic cancer.

\section{Discussion and conclusions}

Tuberculosis is a common disease in undeveloped countries. Due to increasing immigration and cases of HIV-mediated immunosuppression its incidence has recently increased in western countries [23], thus a concurrent increase in the misdiagnosis of tuberculosis can be expected in these countries. Pulmonary tuberculosis is the most frequent presenting form, and intra-abdominal forms of tuberculosis are uncommon [24-26]. Intra-abdominal tuberculosis occurs in $3.5 \%$ of patients with extra-pulmonary tuberculosis [27], and patients with the condition can present with a myriad of non-specific symptoms so diagnosis requires a high level of suspicion [28]. 

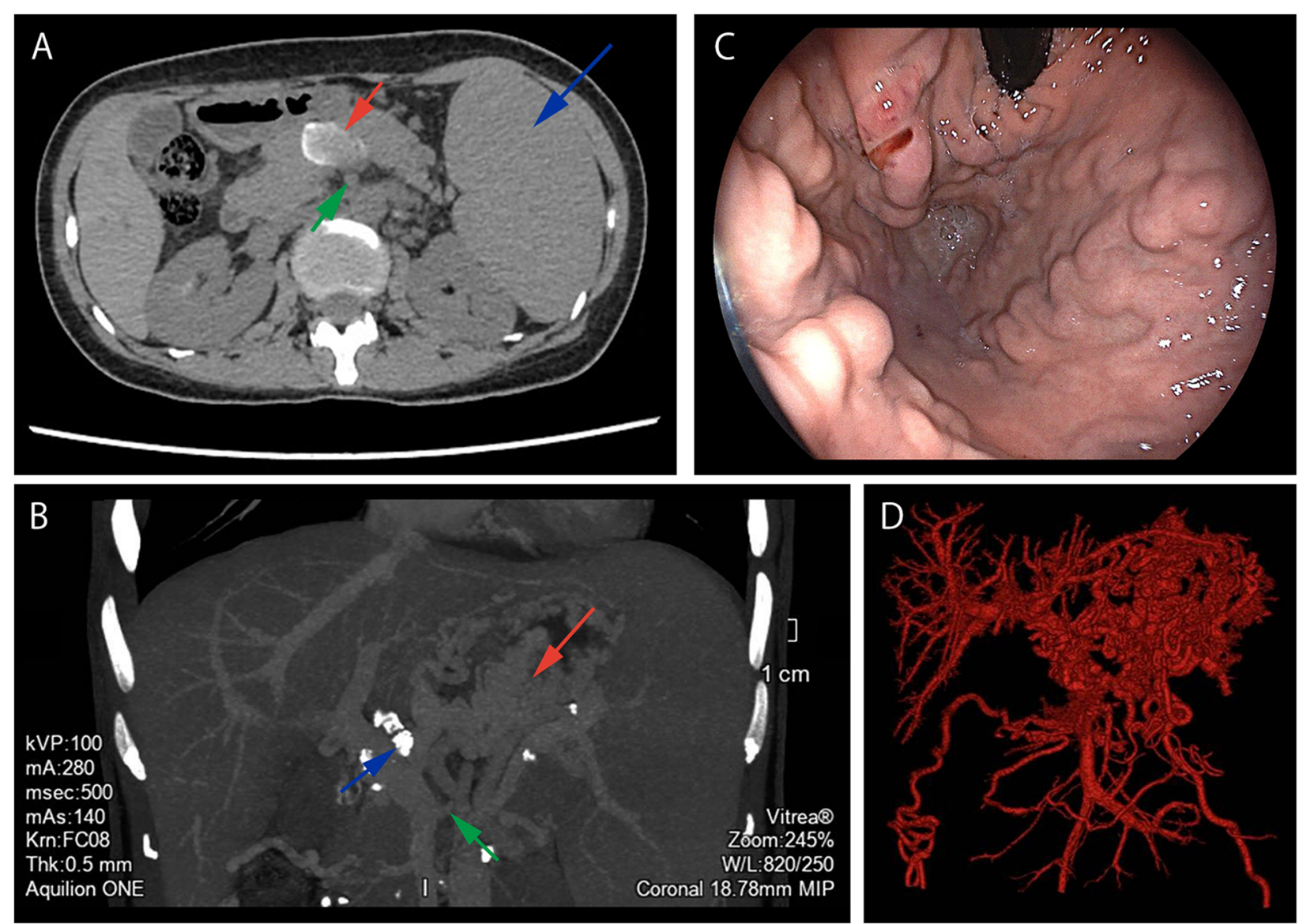

Fig. 1 Computed tomography and gastroscopy images. a Non-contrast computed tomography imaging on a horizontal plane. There is a lowdensity and heterogeneous mass in the pancreas body with an irregular margin (red arrow). The spleen is enlarged (blue arrow), and there are dense nodular shadows around the pancreas (green arrow). b Computed tomography angiography image in the portal venous phase obtained in a coronal plane. Varicose gastric veins (red arrow) and swollen calcified lymph nodes (blue arrow) are evident. The initial section of the splenic vein becomes narrow (green arrow). c Gastroscopy image depicting a varicose vein in the gastric fundus. $\mathbf{d}$ Portal-phase three-dimensional vascular reconstruction image depicting varicose gastric veins and normal esophageal portal veins

Because of the above-described considerations intraabdominal tuberculosis has evidently often been misdiagnosed as a tumor such as intra-abdominal lymphoma, gastrointestinal stromal tumor, ovarian carcinoma, and particularly, peritoneal carcinomatosis [29-33]. Intra-abdominal tuberculosis frequently causes nonspecific symptoms, and these symptoms mainly result from mechanical pull and compression. Konstantara et al. [34] reported a case of small intestine volvulus due to intraabdominal lymphatic tuberculosis, and obstruction jaundice caused by intra-abdominal tuberculosis has also been reported [35]. The current patient who suffered from LSPH resulting from peripancreatic lymph node tuberculosis had been misdiagnosed with pancreatic cancer 7 years prior at another hospital.

Due to a lack of specific symptoms, patients with peripancreatic lymph node tuberculosis primarily present with abdominal pain, constitutional syndrome, jaundice, emaciation, and pancreatitis or an abdominal mass, which are similar to symptoms of pancreatic cancer. There is also a high degree of similarity between the radiological manifestations of peripancreatic lymph node tuberculosis and pancreatic cancer [20, 25, 36-39]. Due to all of these factors peripancreatic lymph node tuberculosis is frequently misdiagnosed as pancreatic cancer. Notably however, the therapeutic approaches to these two diseases are completely different; thus it is important to make a correct diagnosis, in order to avoid unnecessary surgery and long-term complications. For these reasons EUS-FNAB was utilized to distinguish peripancreatic lymph node tuberculosis from pancreatic cancer via Ziehl-Neelsen staining and M. tuberculosis culture [39-44].

EUS-FNAB has higher specificity and sensitivity for the differential diagnosis of pancreatic mass than traditional imaging techniques, and it has now been utilized extensively [45-48]. It was the use of EUS-FNAB that prevented the application of unnecessary surgery. 

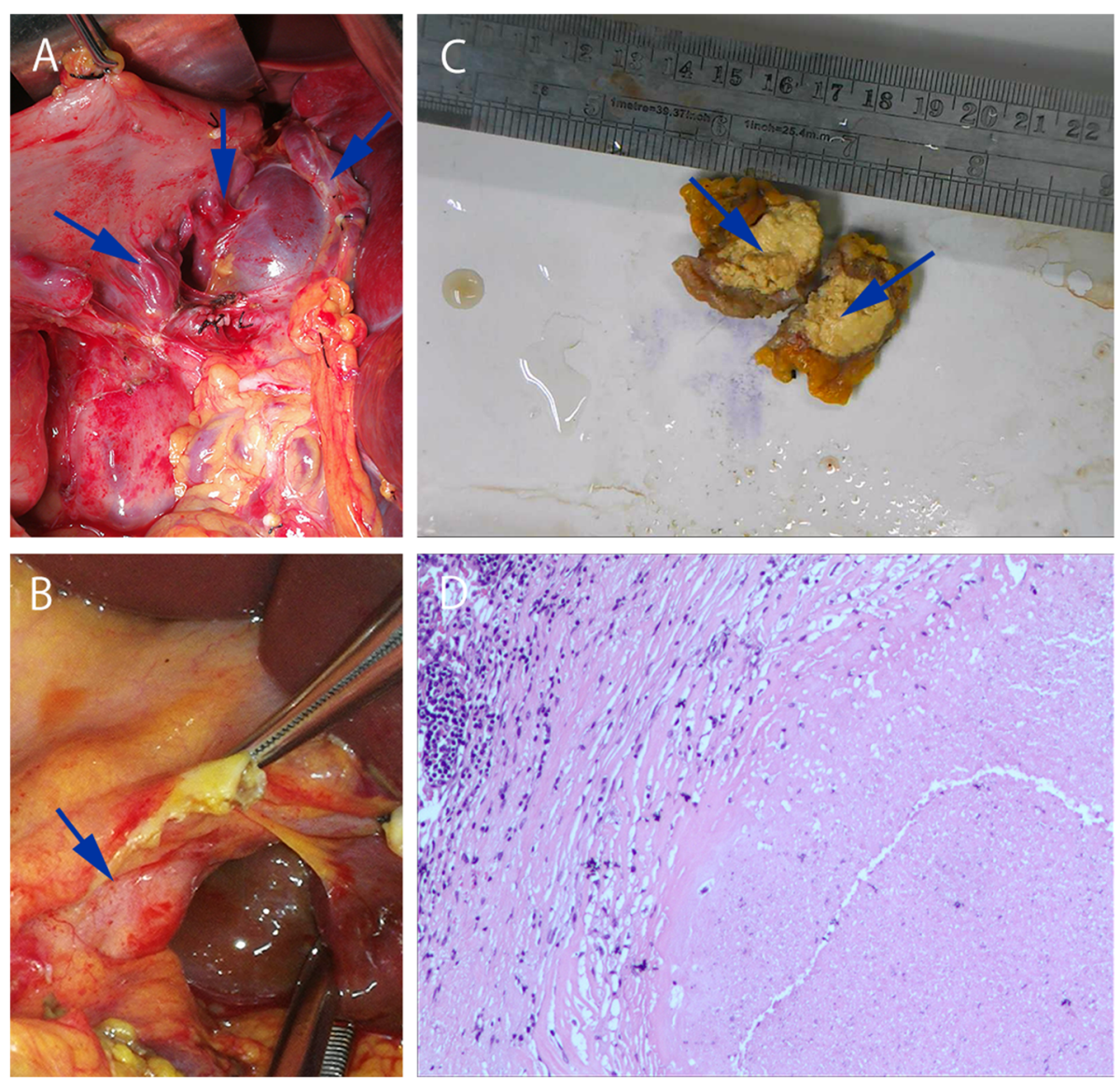

Fig. 2 Intraoperative observations and specimens. a Varicose gastric veins (blue arrow). b An enlarged peripancreatic lymph node (blue arrow). c Macroscopic aspects of the swelling in the peripancreatic lymph nodes. The swollen peripancreatic lymph nodes exhibit caseous necrosis (blue arrow). d Hematoxylin-eosin staining reveals red staining and structureless particles in the background of lymphocytes

Notably however, the accuracy of these tests depends on sample quality and M. tuberculosis activity, and the application of EUS-FNAB for aspiration can be difficult at some sites [49]. In the present case the mass was located in the lower margin of the pancreas body, and peripancreatic blood vessels were abundant, so it is difficult and dangerous to operate aspiration. The surgery was mainly designed to relieve gastrointestinal bleeding caused by LSPH, but it ultimately facilitated a specific diagnosis in the present case. Laparoscopic surgery may be a better option in cases in which surgery is performed solely for diagnostic purposes. Moreover, tuberculosis history, adenosine deaminase, the interferon gamma release assay, and tuberculous polymerase chain reaction analysis can be useful for the diagnosis of lymph node tuberculosis $[3,50]$.

In patients with normal liver function LSPH usually results from splenic vein obstruction or pancreatic inflammatory or neoplastic disease [6]. In the current patient swollen lymph node compression or fibrous scarring after caseous necrosis were the most likely causes. The diagnosis of LSPH is based on clinical, biochemical, and radiological evaluations. Many patients with LSPH are asymptomatic or have primary disease symptoms [13, 14, 51], but in the few LSPH patients who express isolated gastric venous bleeding and anemia the bleeding is usually substantial $[6,9,12]$.

Routine blood tests can reveal reductions in red blood cells, lymphocytes, and platelets. Biochemical evaluation is mainly used to exclude cirrhotic portal hypertension and identify primary disease. In addition to clinical symptoms, imaging plays an important role in confirming the diagnosis in the majority of cases [52]. Although angiography of the splenic vein remains the gold standard for diagnosing LSPH, it is now rarely used because it is invasive and entails a possibility of morbidity [53]. Transabdominal ultrasonography is often the initial imaging modality utilized, but its accuracy for the detection of splenic or superior mesenteric vein thrombosis is questionable [54].

Endoscopic ultrasonography has recently been used to evaluate the portal vasculature, and it is reportedly more 
accurate than transabdominal ultrasonography for evaluating the patency of the splenic vein $[13,55]$. With the rapid development of both $\mathrm{CT}$ and endoscopy, the combination of multidetector CTA, gastroscopy, and portalphase three-dimensional vascular reconstruction may be a better option, as suggested by the current case. CTA and portal-phase three-dimensional vascular reconstruction results can reportedly guide the operation if necessary. Magnetic resonance angiography is a promising method for evaluating the portal venous system [56].

Whether asymptomatic patients require treatment remains controversial, but it is necessary to intervene to prevent active bleeding. In addition to addressing bleeding, it is often necessary to treat the primary disease [16, $17,19,57,58]$. Based on the patient's clinical condition, there are several methods that can be used to relieve isolated gastric bleeding. To reduce venous blood reflux, splenectomy remains the preferred treatment for patients with gastric bleeding due to LSPH, and splenic artery embolization can be used as a supplementary measure in patients in whom splenectomy is deemed unsuitable [13, 16, 17, 19, 57-59]. Moreover, while endoscopic therapy is highly advantageous for the treatment of acute massive gastric bleeding, rebleeding is unavoidable [60-63]. We are also currently investigating whether LSPH due to mechanical compression can be corrected via stent implantation. In the therapeutic procedures utilized in the current patient, a splenectomy and varicose vein dissection were performed for hypersplenism and severe varices intervention, but notably the treatment of each patient with LSPH should be individually tailored to maximize the benefits conferred to that individual patient.

In conclusion, herein we have described a very interesting case. Due to a prior misdiagnosis a 29-year-old woman suffered from LSPH, which resulted from peripancreatic lymph node tuberculosis. LSPH is an extremely rare clinical syndrome, and the current case constitutes the first reported account of LSPH caused by peripancreatic lymph node tuberculosis. The dissemination of the details of this case is necessary in order to provide a reference for the clinical diagnosis and treatment of LSPH.

\section{Abbreviations}

CT: Computed tomography; CTA: Computed tomography angiography; EUSFNAB: Endoscopic ultrasound-guided fine-needle aspiration biopsy;

LSPH: Left-sided portal hypertension

\section{Acknowledgements}

We thank the First People's Hospital of Neijiang for supplying clinical materials, and we thank Charlesworth Author Services (https://www. cwauthors.com/) for editing a draft of this manuscript.

\section{Authors' contributions}

DY and JH wrote the manuscript. JG and $J L$ conceived the report. $X L$ and FX accumulated the clinical materials. All authors contributed to critical revision of the report for important intellectual content. The authors read and approved the final manuscript.

Funding

Not applicable.

Availability of data and materials

Not applicable.

Ethics approval and consent to participate

Not required because the patient was admitted to the hospital for treatment and diagnosis.

\section{Consent for publication}

Written informed consent for publication of their clinical details and clinical images was obtained from the patient.

\section{Competing interests}

The authors declare that they have no competing interests.

\section{Author details}

'Department of General Surgery, Wushan County People's Hospital of Chongqing, Wushan, Chongqing 404700, China. ${ }^{2}$ Department of Hepatobiliary Surgery, The Second Affiliated Hospital of Chongqing Medical University, 74 Linjiang Road, Yuzhong District, Chongqing 400010, China.

${ }^{3}$ Department of Hepatobiliary Surgery, The First People's Hospital of Neijiang, Neijiang 64100, Sichuan, China.

Received: 7 May 2020 Accepted: 11 August 2020

Published online: 18 August 2020

\section{References}

1. Hamzaoui G, Amro L, Sajiai H, Serhane H, Moumen N, Ennezari A, et al. Lymph node tuberculosis: epidemiology, diagnostic and therapeutic aspects, about 357 cases. Pan Afr Med J. 2014;19:157.

2. Ketata W, Rekik WK, Ayadi H, Kammoun S. Extrapulmonary tuberculosis. Rev Pneumol Clin. 2015;71:83-92

3. Popescu MR, Călin G, Strâmbu I, Olaru M, Bălăşoiu M, Huplea V, et al. Lymph node tuberculosis - an attempt of clinico-morphological study and review of the literature. Rom J Morphol Embryol. 2014;55:553-67.

4. Tritar-Cherif F, Daghfous H. Lymph node tuberculosis management. Tunis Med. 2014;92:111-3.

5. Fillion A, Ortega-Deballon P, Al-Samman S, Briault A, Brigand C, Deguelte S, et al. Abdominal tuberculosis in a low prevalence country. Med Mal Infect. 2016;46:140-5.

6. Köklü S, Coban S, Yüksel O, Arhan M. Left-sided portal hypertension. Dig Dis Sci. 2007;52:1141-9.

7. Aikot S, Manappallil RG, Pokkattil S, Kakkattil A. Solid pseudopapillary neoplasm of pancreas: an unusual aetiology for haematochezia. BMJ Case Rep. 2018;2018:bcr2018225332.

8. Csomor J, Bunganič B, Dvořáková D, Hř́bek P, Kmochová K, Campr V, et al. Extramedullary Plasmacytoma of the pancreas complicated with left-sided portal hypertension-a case report and literature review. J Gastrointest Cancer. 2019;50:962-6.

9. Fernandes A, Almeida N, Ferreira AM, Casela A, Gomes D, Portela F, et al. Left-sided portal hypertension: a sinister entity. GE Port J Gastroenterol. 2015;22:234-9.

10. Kushiya H, Noji T, Abo D, Soyama T, Tanaka K, Nakanishi Y, et al. Treatment of bleeding from a portion of pancreatojejunostomy after pancreaticoduodenectomy with division of the splenic vein: two case reports. Surg Case Rep. 2019;5:128.

11. Mizuno S, Kato H, Yamaue H, Fujii T, Satoi S, Saiura A, et al. Left-sided portal hypertension after Pancreaticoduodenectomy with resection of the portal vein/superior mesenteric vein confluence in patients with pancreatic cancer: a project study by the Japanese Society of Hepato-Biliary-Pancreatic Surgery. Ann Surg. 2019. https://doi.org/10.1097/SLA.0000000000003487.

12. Pereira P, Peixoto A. Left-sided portal hypertension: a clinical challenge. GE Port J Gastroenterol. 2015;22:231-3.

13. Köklü S, Yüksel O, Arhan M, Coban S, Başar O, Yolcu OF, et al. Report of 24 left-sided portal hypertension cases: a single-center prospective cohort study. Dig Dis Sci. 2005;50:976-82. 
14. Sakorafas GH, Sarr MG, Farley DR, Farnell MB. The significance of sinistral portal hypertension complicating chronic pancreatitis. Am J Surg. 2000;179:129-33.

15. Sato T, Yamazaki K, Kimura M, Toyota J, Karino Y. Endoscopic color Doppler Ultrasonographic evaluation of gastric varices secondary to left-sided portal hypertension. Diagnostics (Basel). 2014;4:94-103.

16. Lenhart A, Fernandez-Castillo J, Mullins K, Salgia R. A rare case of gastric variceal hemorrhage secondary to infiltrative B-cell lymphoma. Case Rep Gastroenterol. 2016;10:518-24.

17. Lupascu-Ursulescu C, Trofin A-M, Zabara M, Vornicu A, Cadar R, Apopei O, et al. Bleeding from isolated gastric varices as complication of a mucinous cystic neoplasm of the pancreas: a case report. Medicine (Baltimore). 2017; 96:e8775-e.

18. Patel H, Bhandari P, Kumar K, Makker J, Chandrala C. Isolated gastric varices due to essential thrombocytosis related to splenic vein thrombosis: a challenge to uncover the concealed diagnosis. Cureus. 2019;11:e6068-e.

19. Wang X-Q, Yang H-Q, Chen J-X, Mao Z-F, Han H, Chen G, et al. Clinical and pathological analysis of solitary fibrous tumors with portal vein widening: a case report. Medicine (Baltimore). 2019;98:e15757-e.

20. García Del Olmo N, Boscà Robledo A, Penalba Palmí R, Añón Iranzo E, Aguiló LJ. Primary peripancreatic lymph node tuberculosis as a differential diagnosis of pancreatic neoplasia. Rev Esp Enferm Dig. 2017;109:528-30.

21. Hwang $T L$, Jan $Y Y$, Jeng LB, Chen MF, Hung CF, Chiu CT. The different manifestation and outcome between pancreatitis and pancreatic malignancy with left-sided portal hypertension. Int Surg. 1999;84:209-12.

22. Thrainsdottir H, Petursdottir V, Blöndal S, Björnsson ES. Pancreatic mass leading to left-sided portal hypertension, causing bleeding from isolated gastric varices. Case Rep Gastrointest Med. 2014;2014:956490.

23. Sotgiu G, Dara M, Centis R, Matteelli A, Solovic I, Gratziou C, et al. Breaking the barriers: migrants and tuberculosis. Presse Med. 2017;46:e5-e11.

24. Huang C-T, Lo C-Y, Lee T-H. Isolated peripancreatic tuberculous lymphadenopathy: a rare manifestation of abdominal tuberculosis mimicking pancreatic cystic neoplasm. J Dig Dis. 2013;14:105-8.

25. Lee YJ, Hwang J-Y, Park S-E, Kim Y-W, Lee JW. Abdominal tuberculosis with periportal lymph node involvement mimicking pancreatic malignancy in an immunocompetent adolescent. Pediatr Radiol. 2014;44:1450-3.

26. Liang X, Huang X, Yang Q, He J. Calcified peripancreatic lymph nodes in pancreatic and hepatic tuberculosis mimicking pancreatic malignancy: a case report and review of literature. Medicine (Baltimore). 2018;97:e12255-e.

27. Evans RP, Mourad MM, Dvorkin L, Bramhall SR. Hepatic and intra-abdominal tuberculosis: 2016 update. Curr Infect Dis Rep. 2016;18:45.

28. Abdallah M, Larbi T, Hamzaoui S, Mezlini E, Harmel A, Ennafaa M, et al. Abdominal tuberculosis: a retrospective series of 90 cases. Rev Med Interne. 2011:32:212-7

29. Atay H, Kelkitli E, Turgut M. A tuberculosis case mimicking lymphoma. Pan Afr Med J. 2014:17:157.

30. Kim YS, Moon JS, Lee JW, Kim I, Ryu SH, Paik IW. Solitary intra-abdominal tuberculous lymphadenopathy mimicking duodenal GIST. Korean J Intern Med. 2005;20:72-5

31. Meng ZX, Liu Y, Wu R, Shi K, Li T. Tuberculous abdominal cocoon mimicking peritoneal carcinomatosis. Antimicrob Resist Infect Control. 2019;8:108.

32. Ozşeker B, Ozşeker HS, Kav T, Shorbagi A, Karakoç D, Bayraktar Y. Abdominal tuberculosis leading to portal vein thrombosis, mimicking peritoneal carcinomatosis and liver cirrhosis. Acta Clin Belg. 2012;67:137-9.

33. Xu YE, Tan K, Hendahewa R. Intra-abdominal tuberculosis masquerading as ovarian carcinoma. J Surg Case Rep. 2019;2019:rjz361.

34. Konstantara F, Stamopoulou S, Gkegkes ID, Kotrogiannis I, Fotiou E, Papazacharias $C$, et al. Intra-abdominal lymphatic tuberculosis as a rare case of small intestine volvulus. SAGE Open Med Case Rep. 2019;7: $2050313 \times 19844379$.

35. Jazet IM, Perk L, De Roos A, Bolk JH, Arend SM. Obstructive jaundice and hematemesis: two cases with unusual presentations of intra-abdominal tuberculosis. Eur J Intern Med. 2004;15:259-61.

36. Cherian JV, Somasundaram A, Ponnusamy RP, Venkataraman J. Peripancreatic tuberculous lymphadenopathy. An impostor posing diagnostic difficulty. JOP. 2007:8:326-9.

37. Kim J-B, Lee SS, Kim S-H, Byun JH, Park DH, Lee TY, et al. Peripancreatic tuberculous lymphadenopathy masquerading as pancreatic malignancy: a single-center experience. J Gastroenterol Hepatol. 2014;29:409-16.

38. Li Y, Yang Z-G, Guo Y-K, Min P-Q, Yu J-Q, Ma E-S, et al. Distribution and characteristics of hematogenous disseminated tuberculosis within the abdomen on contrast-enhanced CT. Abdom Imaging. 2007;32:484-8.
39. Yamada R, Inoue H, Yoshizawa N, Kitade T, Tano S, Sakuno T, et al. Peripancreatic tuberculous lymphadenitis with biliary obstruction diagnosed by endoscopic ultrasound-guided fine-needle aspiration biopsy. Intern Med. 2016:55:919-23.

40. Arai J, Kitamura K, Yamamiya A, Ishii Y, Nomoto T, Honma T, et al. Peripancreatic tuberculous lymphadenitis diagnosed via endoscopic ultrasound-guided fine-needle aspiration and polymerase chain reaction. Intern Med. 2017;56:1049-52.

41. Boujaoude J-D, Honein K, Yaghi C, Ghora C, Abadjian G, Sayegh R. Diagnosis by endoscopic ultrasound guided fine needle aspiration of tuberculous lymphadenitis involving the peripancreatic lymph nodes: a case report. World J Gastroenterol. 2007;13:474-7.

42. Dutta U, Shrestha D, Sharma A, Gupta P, Das A, Srinivasan R, et al. Implantation cutaneous tuberculosis after ultrasound-guided fine needle aspiration cytology. BJR Case Rep. 2016;2:20150393.

43. Furuhashi H, Abe H, Yoshizawa K, Hirose Y, Miura Y, Seki N, et al. A case of peripancreatic tuberculous lymphadenitis diagnosed by endoscopic ultrasound-guided fine-needle aspiration. Clin J Gastroenterol. 2014;7:68-73.

44. Itaba S, Yoshinaga S, Nakamura K, Mizutani T, Honda K, Takayanagi R, et al. Endoscopic ultrasound-guided fine-needle aspiration for the diagnosis of peripancreatic tuberculous Iymphadenitis. J Gastroenterol. 2007:42:83-6.

45. Abdelkader A, Hunt B, Hartley CP, Panarelli NC, Giorgadze T. Cystic lesions of the pancreas: differential diagnosis and Cytologic-histologic correlation. Arch Pathol Lab Med. 2020;144:47-61.

46. Fitzpatrick MJ, Hernandez-Barco YG, Krishnan K, Brugge W, Casey B, Pitman MB. Diagnostic yield of the SharkCore EUS-guided fine-needle biopsy. J Am Soc Cytopathol. 2019;8:212-9.

47. Hedenström P, Demir A, Khodakaram K, Nilsson O, Sadik R. EUS-guided reverse bevel fine-needle biopsy sampling and open tip fine-needle aspiration in solid pancreatic lesions - a prospective, comparative study. Scand J Gastroenterol. 2018;53:231-7.

48. Kitano M, Yoshida T, Itonaga M, Tamura T, Hatamaru K, Yamashita Y. Impact of endoscopic ultrasonography on diagnosis of pancreatic cancer. $J$ Gastroenterol. 2019:54:19-32.

49. Rana A, Rana SS. Endoscopic ultrasound-guided tissue acquisition: techniques and challenges. J Cytol. 2019;36:1-7.

50. Jia H, Pan L, Du B, Sun Q, Wei R, Xing A, et al. Diagnostic performance of interferon- $\gamma$ release assay for lymph node tuberculosis. Diagn Microbiol Infect Dis. 2016;85:56-60.

51. Wang L, Liu G-J, Chen Y-X, Dong H-P, Wang L-X. Sinistral portal hypertension: clinical features and surgical treatment of chronic splenic vein occlusion. Med Princ Pract. 2012;21:20-3.

52. Weber SM, Rikkers LF. Splenic vein thrombosis and gastrointestinal bleeding in chronic pancreatitis. World J Surg. 2003;27:1271-4.

53. Leger $L$, Lenriot JP, Lemaigre $G$. Hypertension and segmental portal stasis in chronic pancreatitis. Apropos of 126 cases examined by splenoportography and splenomanometry. J Chir (Paris). 1968;95:599-608.

54. Lewis JD, Faigel DO, Morris JB, Siegelman ES, Kochman ML. Splenic vein thrombosis secondary to focal pancreatitis diagnosed by endoscopic ultrasonography. J Clin Gastroenterol. 1998;26:54-6.

55. Garcia-Tsao G, Sanyal AJ, Grace ND, Carey W, Practice Guidelines Committee of the American Association for the Study of Liver D, Practice Parameters Committee of the American College of G. Prevention and management of gastroesophageal varices and variceal hemorrhage in cirrhosis. Hepatology. 2007:46:922-38

56. Hughes LA, Hartnell GG, Finn JP, Longmaid HE, Volpe J, Wheeler HG, et al. Time-of-flight MR angiography of the portal venous system: value compared with other imaging procedures. AJR Am J Roentgenol. 1996;166:375-8.

57. Di Martino M, de la Hoz RA, Real Martínez Y, Martín-Pérez E. Left-sided portal hypertension due to retroperitoneal fibrosis treated with an oesophagus preserving, modified Sugiura procedure. Ann R Coll Surg Engl. 2020;102:e48-50.

58. Ozsay O, Gungor F, Karaisli S, Kokulu I, Dilek ON. Hydatid cyst of the pancreas causing both acute pancreatitis and splenic vein thrombosis. Ann R Coll Surg Engl. 2018;100:e178-e80.

59. Chalyı̆ AN, Zubarev PN, Kotiv BN. Left-sided portal hypertension: pathogenesis and treatment. Vestn Khir Im I I Grek. 1997;156:65-9.

60. Colaneri RP, Coelho FF, de Cleva R, Herman P. Laparoscopic treatment of Presinusoidal Schistosomal portal hypertension associated with postoperative endoscopic treatment: results of a new approach. Surg Laparosc Endosc Percutan Tech. 2017;27:90-3. 
61. Tian L, He Y, Li D, Zhang H. Surgical shunts compared with endoscopic sclerotherapy for the treatment of variceal bleeding in adults with portal hypertension: a systematic review and meta-analysis. Postgrad Med J. 2018; 94:7-14.

62. Tornikidis J, Hoch J, Pádr R, Keil R. Massive bleeding in portal hypertension endoscopic, surgical or endovascular management? Rozhl Chir. 2017;96:390-3.

63. Xiaoging Z, Na L, Lili M, Jie C, Tiancheng L, Jian W, et al. Endoscopic cyanoacrylate injection with Lauromacrogol for gastric varices: long-term outcomes and predictors in a retrospective cohort study. J Laparoendosc Adv Surg Tech A. 2019;29:1135-43.

\section{Publisher's Note}

Springer Nature remains neutral with regard to jurisdictional claims in published maps and institutional affiliations.

Ready to submit your research? Choose BMC and benefit from:

- fast, convenient online submission

- thorough peer review by experienced researchers in your field

- rapid publication on acceptance

- support for research data, including large and complex data types

- gold Open Access which fosters wider collaboration and increased citations

- maximum visibility for your research: over $100 \mathrm{M}$ website views per year

At BMC, research is always in progress.

Learn more biomedcentral.com/submissions 